Article

\title{
Post-1990s College Students Academic Sustainability: The Role of Negative Emotions, Achievement Goals, and Self-efficacy on Academic Performance
}

\author{
Xinqiao Liu ${ }^{1,2, *}$, Xueheng Gao ${ }^{1}$ and Siqing Ping ${ }^{3, *}$ \\ 1 Graduate School of Education, Peking University, Beijing 100871, China; xueheng@pku.edu.cn \\ 2 China Institute for Educational Finance Research, Peking University, Beijing 100871, China \\ 3 Department of Public Administration, Guangzhou Administration School, Guangzhou 510070, China \\ * Correspondence: xinqiaoliu@pku.edu.cn (X.L.); pingsq@gzswdx.gov.cn (S.P.)
}

Received: 14 December 2018; Accepted: 30 January 2019; Published: 1 February 2019

\begin{abstract}
In 1982, the "one-child policy" was implemented by China's Constitution, which led to the majority of post-1990s college students in China being the only child in their family. Unique characteristics have been demonstrated in psychological development of post-1990s Chinese college students due to the lack of sibling companionship, and the relationship between their psychological state and academic performance can affect their future academic sustainability. This paper used Beijing College Students Panel Survey (BCSPS) data to study the role of negative emotions, achievement goals, and academic self-efficacy on academic performance and gives a panoramic description of the China's post-1990s college students' psychological states based on the four-year data of more than 2000 college students who enrolled in 2008. We then used regression analysis and a two-way fixed effect model to study the effects of the psychological state on academic performance. The research conclusions of the study are as follows: (1) The levels of negative emotions, achievement goals, and academic self-efficacy vary according to the grade and gender of college students; (2) among all negative emotions discussed, only anxiety presents a significant predictive effect on academic performance, while the effect of stress and depression is not significant; (3) the presence of level of mastery-approach goals is higher than the other three achievement goals, and college students' academic self-efficacy keeps decreasing from freshman to junior year; (4) performance-approach goals and academic self-efficacy are identified as having a significant promoting effect on academic performance; (5) mastery-avoidance goals and performance-avoidance goals are proven to have a negative effect on academic performance. This paper discusses the contribution of the psychological sustainability and sustainable development to college students' academic performance from a primary intervention perspective. We believe that it is feasible to improve academic achievement by improving noncognitive factors, such as mental state, to achieve academic sustainability.
\end{abstract}

Keywords: post-1990s college students in China; academic sustainability; negative emotions; achievement goals; academic self-efficacy; academic performance; sustainable development

\section{Introduction}

Post-1990s college students in China were raised in an era when China's economy and social structure were rapidly developing and undergoing a tremendous transformation, and the implementation of the "one-child policy" also brought great changes to Chinese family structure. The majority of the post-1990s college students were brought up as the only child in the family without the companionship of siblings. Although raised in a relatively better-off environment, they are often 
described as being solitary, fragile, sensitive, and lonely, and having poor mental endurance [1-3]. The psychology of sustainability and sustainable development calls for new awareness of the need to achieve sustainable well-being from a primary prevention, which aims at preventing a problem before it starts and promoting psychological well-being at the same time [4]. From this point of view, college is not only a place for enriching professional skills but also a place for a person to become independent and form stable personality structures and cultivate profound adaptability and pressure-bearing ability to survive in broader society. The psychology of sustainability and sustainable development incorporates spatial and temporal perspectives, harmonizing complexity in relation to each person and the others [5] and constructing authentic meanings for individuals and communities [6]. It can therefore be seen as a new approach to promoting well-being in organizations [7]. China's education system has produced notably high learning outcomes, but it has also created a competitive and anxious atmosphere among students [8]. Under this circumstance, new challenges for universities include correctly understanding the psychological state of the post-1990s college students and catering to them in curriculum plans, daily management decisions, and student activities, so as to scientifically guide the students to the establishment of a sound personality, promote their psychological health, and improve their academic performance. Sustainable education aims to improve skills that encourage students to reflect on their actions, and personality traits are an important and significant factor for students' abilities to overcome depression [9]. While there is no method to improve cognitive factors such as IQ in the short term, noncognitive factors, such as psychological state, can be modified in certain ways. Therefore, the impact and mechanism of psychological states on students' academic performance are worth exploring.

Current research focusing on the factors influencing the impact college students' psychological states on their academic performance is mostly built on data from cross-sectional questionnaires, which could cause contingencies in the analysis. The students' psychological state and its impact on academic performance cannot be compared over time because the questionnaires were sampled at a one-panel spot. If tracking data can be used, more accurate and objective conclusions can be reached, since the influence of the psychological state can be observed long-term. This study attempts to understand the effects and mechanisms of negative emotions, achievement goals, and academic self-efficacy on academic performance using longitudinal data, and then discuss the contribution of the psychology of sustainability and sustainable development to college students in academic performance from a primary prevention perspective. The names of the variables this paper used can be clarified as follows.

Negative emotions: Depression, anxiety and stress; motivational variables: Approaching-avoidance goals and self-efficacy beliefs; academic performance: Academic rank.

\subsection{Negative Emotions}

Experiencing negative emotions is quite common for college students [10], and the mental health of college students deserves more attention. The negative emotions discussed in this paper consist of anxiety, depression, and stress. Research has shown support for the relationship between negative emotions and academic performance [11]. High levels of anxiety and depression have been found to have a negative effect on students' academic performance [12,13], and students with more academic stress are also more likely to perform poorly in academic achievement [14]. Aronen et al. reported that anxiety and depression can affect memory as well as concentration, which leads to poor academic performance [15]. Depression is found to have a significant mediation effect between physical activity and academic performance [16], and stress is also proven to obstruct both academic performance and psychosocial and physiological functioning as an emotional response with adaptive function [17]. Although anxiety, depression, and stress are all classified as negative emotions, their impacts on academic performance are not entirely consistent in previous studies. Furthermore, unlike in primary and secondary schools, improving academic performance is no longer the only target for college students, which indicates that the mechanism of how negative emotions affect college students' academic performance still requires further discussion. 


\subsection{Achievement Goals}

Achievement goal refers to the purpose that an individual holds when engaged in achievement-related activities which will affect one's cognitive process and determine their behavior [18]. Different achievement goals will lead to different interpretations and coping styles, and the primary research emphasis has been on two goal types: Mastery goals and performance goals $[19,20]$. Mastery goals focus on the development of competence through task mastery, which involves improving one's own abilities and adopting self-reference criteria, whereas performance goals focus on the demonstration of competence relative to others and adopting the criteria of social comparison [21]. The achievement goals framework is developed on the basis of achievement goal theory, and the latter is revised to include the distinction between approach and avoidance motivation. Approach motivation refers to achieving the corresponding goal through one's own efforts, while avoidance motivation focuses on avoiding or eliminating undesired outcomes. Therefore, the original mastery-performance goal dichotomy can be developed into a quadruple method of $2 * 2$ framework, including mastery-approach goals, mastery-avoidance goals, performance-approach goals, and performance-avoidance goals [22]. According to the latest research, it is not appropriate to use "goals" to represent desired results or end states. The definition of achievement goal is also a future-focused cognitive representation that guides behavior to a competence-related end state that the individual has committed to either approaching or avoiding [23]. The latest definition mirrors the complex purpose and goal conceptualizations of achievement goals [24]. Studies on the effect of mastery goals on academic performance have basically reached the same conclusion that individuals with high mastery goals will strive to be enterprising and successful, whether the subjects involved are primary school students $[25,26]$ or college students $[27,28]$. For example, students' first year GPA was associated with mastery-approach goals, and thus, educational interventions can be provided to the students who show lower levels of mastery-approach goals to prevent academic failure [29]. Performance goals are identified to have two basic defining components, including an appearance component and a normative component. Within the appearance component, performance is defined by demonstration and affirmation of competence to an audience, and within the normative component, performance is defined based on normative social comparisons. Mastery goals are divided according to the standard for evaluating the task, namely task goals, or according to one's intrapersonal development, namely learning goals [30]. According to Abramson, Metalsky, and Alloy, the disparity between the definition of approach goals and the participants' subjective estimation of their academic competence could cause the results of the performance-approach goal to be controversial [31]. Individuals who are performance-avoidant more easily become anxious and worry about undesirable evaluations, which leads to unsatisfying academic performance [32].

\subsection{Academic Self-Efficacy}

An individual's judgment of how well one can execute courses of action required to deal with prospective situations is called self-efficacy [33]. High self-efficacy groups can promote learning progress with more effective cognitive strategies and time management strategies and, therefore, are more confident when completing a task, which enables them to adopt a calm and thoughtful method of accomplishment [34]. The skills and abilities required are different across different fields, so there is no universal self-efficacy skill applicable to all situations [35]. Within an academic context, self-efficacy is frequently described in terms of academic self-efficacy (AS), which defines a learner's judgment on their ability to control learning behavior and academic performance and is not necessarily related to their real abilities, and certain research is mainly focused on the assessment of learners' self-confidence in whether they can use their abilities or skills to complete learning tasks. Research has confirmed that a relationship exists between academic self-efficacy and academic performance [36,37], both in high school [38] and at university [37]. Academic self-efficacy is an important predictor of academic performance [39], and its positive effect has been confirmed by various complex models [40-43]. Although the relationship between academic self-efficacy and 
academic performance has been clarified [44], the mechanism of academic self-efficacy on academic performance is still worth discussing when negative emotions such as anxiety, depression, and stress are involved.

\subsection{Hypothesis}

Based on research that studies the relationship between negative emotions, achievement goals, academic self-efficacy, and academic performance, the following five hypotheses can be put forward.

Hypothesis 1 (H1). Correlations exist between college students' academic performance and their negative emotions, achievement goals, and academic self-efficacy.

Hypothesis 2 (H2). Anxiety, depression, and stress have different effects on academic performance.

Hypothesis 3 (H3). College students' approach goals and avoidance goals have opposite effects on their academic performance.

Hypothesis 4 (H4). Improvement of college students' academic self-efficacy can lead to the promotion of their academic achievements.

Hypothesis 5 (H5). Mastery goals are negatively related to negative emotions and positively related with academic achievement.

\section{Methods}

\subsection{Participants}

This study used data from the "Beijing College Student Panel Survey" (BCSPS) of the "China Education Panel Survey" (CEPS). The sampling frame of this survey was the Students' status data bank provided by the Beijing Education Committee, and 5100 students who enrolled in college in 2006 and 2008 were involved. This survey adopted a probability proportionate to size (PPS) sampling method, and the sampling units of each of the stages were as follows: The first stage: Taking universities as the primary sampling unit; the second stage: Taking majors as the secondary sampling unit; the third stage: Taking individuals as the final sampling unit [45].

We divided colleges involved in the survey into 6 groups according to administrative affiliation and inclusion in the "211 Project". Participants of Peking University, Tsinghua University, and Renmin University of China were separately stratified into 3 groups and a total of six sampling frames were constructed: Sampling frame 1: Peking University; sampling frame 2: Renmin University of China; sampling frame 3: Tsinghua University; sampling frame 4: Universities of the "211 Project" that are directly affiliated with the Ministry of Education or other Ministries; sampling frame 5: All non-211 Project universities that are directly affiliated with the Ministry of Education or other ministries; sampling frame 6: All universities affiliated with the Municipality of Beijing [45].

The survey adopted a multistage sampling plan and used a two-stage PPS in three separate stratified universities: Peking University, Renmin University of China, and Tsinghua University (sampling frames 1, 2, and 3). Academic majors and individuals were taken as primary and final sampling units. In the primary sampling unit, 25 majors were selected from each university; in the final sampling unit, 20 students were selected from each major. In other sampling frames (sampling frames 4,5 , and 6), the number of schools sampled was roughly proportional to the number of students of each frame. For the primary sampling unit, six universities were selected in sampling frame 4, two universities in sampling frame 5 , and four universities in sampling frame 6 . In the secondary sampling unit, 15 majors were selected from each university. In the final sampling unit, 20 students were selected from each major [45]. 
The "Beijing College Student Panel Survey" (BCSPS) taken in 2009 and 2010 was carried out on-site with the cooperation and assistance of the Beijing Municipal Committee of Teachers and Workers and the Department of Students' Affairs of the schools. The survey in 2011 was conducted entirely online by sending short messages and e-mails to the participants and inviting them to log in to the questionnaire website with a unique code [45].

The first to the fourth rounds of the survey covered the mental state and academic performance of students enrolled in 2008 from their freshman to senior year as tracking data, and therefore, they were selected as the sample for this study, which can meet both the consistency and scientific nature that research requires. The original designed sample size was 2564 students, and 2473 valid samples were collected in the first round, and the recovery rate of the base period was $96.45 \%$. The second, third, and fourth rounds each collected 2356, 2341, and 2240 valid samples, respectively, and the follow-up rate was $95.27 \%, 94.66 \%$, and $90.58 \%$, respectively. The follow-up rate of the panel data was over $90 \%$, with very few sample losses and a profound data tracking effect. In order to ensure the consistency of the data and to investigate the four-year trend of the same university, samples that did not participate in all four rounds of the survey were removed from the database. Based on that, we also eliminated samples who were reported to have a negative academic rank (academic rank $<0$ ) from the database, and the 2057 remaining samples entered the research. The distribution of samples in each survey round and in each school are shown in Tables 1 and 2.

Table 1. Frequency and percentage of samples.

\begin{tabular}{cccccc}
\hline \multirow{2}{*}{ Round } & \multicolumn{3}{c}{ Original Data } & \multicolumn{2}{c}{ Processed Date } \\
\cline { 2 - 6 } & Frequency & Percentage & Follow-Up Rate (\%) & Frequency & Percentage \\
\hline 1 & 2473 & 26.3 & - & 2057 & 25 \\
2 & 2356 & 25 & 95.27 & 2057 & 25 \\
3 & 2341 & 24.9 & 94.66 & 2057 & 25 \\
4 & 2240 & 23.8 & 90.58 & 2057 & 25 \\
Total & 9410 & 100 & - & 8228 & 100 \\
\hline
\end{tabular}

Table 2. The sample size of different universities.

\begin{tabular}{|c|c|c|c|c|}
\hline University & $\begin{array}{c}\text { Processed } \\
\text { Sample Size }\end{array}$ & Proportion (\%) & $\begin{array}{c}\text { Initial } \\
\text { Sample Size }\end{array}$ & Proportion (\%) \\
\hline North China University of Technology & 132 & 6.4 & 151 & 6.11 \\
\hline Beihang University & 128 & 6.2 & 153 & 6.19 \\
\hline Beijing University of Chemical Technology & 134 & 6.5 & 142 & 5.74 \\
\hline Beijing Institute of Technology & 145 & 7.0 & 157 & 6.35 \\
\hline $\begin{array}{c}\text { Beijing Institute of Petroleum and Chemical } \\
\text { Technology }\end{array}$ & 125 & 6.1 & 136 & 5.50 \\
\hline $\begin{array}{c}\text { Beijing University of Posts and } \\
\text { Telecommunications }\end{array}$ & 110 & 5.3 & 128 & 5.18 \\
\hline Beijing Language and Culture University & 119 & 5.8 & 161 & 6.51 \\
\hline Tsinghua University & 201 & 9.8 & 257 & 10.39 \\
\hline Renmin University of China & 203 & 9.9 & 245 & 9.91 \\
\hline Minzu University of China & 119 & 5.8 & 160 & 6.47 \\
\hline Total & 2057 & 100.0 & 2473 & 100.0 \\
\hline
\end{tabular}

\subsection{Measure}

Emotions were assessed using the DASS (Depression-Anxiety-Stress Scale, Appendix A), which has shown satisfactory homogeneity reliability and profound criterion-related validity, content validity, and structural validity in a series of studies across different countries with different samples. A lower 
score indicates a lower level of anxiety, depression, and stress of the subject. The measurement of achievement goals is adapted from the achievement goal framework (Appendix B), which comprises four dimensions: Mastery-approach goals, mastery-avoidance goals, performance-approach goals, and performance-avoidance goals [22]. The higher the score is, the better the sample fits to the respective dimension. Academic self-efficacy is measured using the academic self-efficacy scale of the PALS (Patterns of Adaptive Learning Scales) questionnaire (Appendix C), and a higher score demonstrates better academic self-efficacy. Academic performance is based on the percentage of ranks in the class that individual reports, and this percentage has a negative relationship with the academic performance. We tested the scale reliability coefficient of the DASS scale, achievement goal scale, and academic self-efficacy scale. In the achievement goal questionnaire, the scale reliability coefficients of the mastery-approach, performance-approach, mastery-avoidance, and performance-avoidance goals are $0.767,0.826,0.778$, and 0.634 , respectively. In the DASS scale, the scale reliability coefficients of anxiety, depression, and stress are $0.882,0.895$, and 0.897 , respectively. In academic self-efficacy scale, the scale reliability coefficient is 0.877 .

\section{Results}

\subsection{Descriptive Analysis}

Table 3 presents the mean, standard deviation, minimum, median, and maximum values of all variables in the four-year follow-up survey. Gender was designed to be a dummy variable, with female defined as 0 and male defined as 1 . Table 3 shows that the average value for the dummy variable of gender is 0.47 , which indicates that $47 \%$ of the samples are male and $53 \%$ are female. Table 4 presents mean and standard errors of mental state in all grades.

Table 3. Descriptive statistics for all variables.

\begin{tabular}{cccccccc}
\hline VarName & Obs & Mean & SD & Min & Median & Max & Range \\
\hline AR & 8210 & 42.74 & 24.53 & 0 & 42.11 & 100 & {$[0,100]$} \\
Gender & 8228 & 0.47 & 0.50 & 0 & 0 & 1 & {$[0,1]$} \\
Stress & 8228 & 12.13 & 6.98 & 0 & 12 & 42 & {$[0,42]$} \\
Depression & 8228 & 7.34 & 6.37 & 0 & 6 & 42 & {$[0,42]$} \\
Anxiety & 8228 & 7.67 & 6.46 & 0 & 6 & 42 & {$[0,42]$} \\
PAP & 8228 & 9.97 & 2.91 & 3 & 10 & 15 & {$[3,15]$} \\
MAV & 8228 & 9.41 & 2.77 & 3 & 9 & 15 & {$[3,15]$} \\
MAP & 8228 & 11.09 & 2.63 & 3 & 11 & 15 & {$[3,15]$} \\
PAV & 8228 & 9.06 & 2.66 & 3 & 9 & 15 & {$[3,15]$} \\
AS & 8228 & 17.81 & 4.15 & 5 & 18 & 25 & {$[5,25]$} \\
\hline
\end{tabular}

Note: $\mathrm{AR}=$ academic rank, $\mathrm{PAP}=$ performance-approach goals, MAV = mastery-avoidance goals, $\mathrm{MAP}=$ mastery-approach goals, $\mathrm{PAV}=$ performance-avoidance goals, and $\mathrm{AS}=$ academic self-efficacy.

Table 4. Mean and standard errors of mental state in all grades.

\begin{tabular}{cccccccccc}
\hline Grade & & Stress & Depression & Anxiety & PAP & MAV & MAP & PAV & AS \\
\hline \multirow{2}{*}{ Freshman } & Mean & 12.64 & 7.21 & 7.67 & 10.43 & 9.96 & 11.81 & 9.05 & 18.12 \\
& S.E. & 6.81 & 5.75 & 5.76 & 3.04 & 2.86 & 2.54 & 2.77 & 4.39 \\
Sophomore & Mean & 13.04 & 7.47 & 7.94 & 10.10 & 9.55 & 11.26 & 8.97 & 17.98 \\
& S.E. & 6.96 & 6.15 & 6.12 & 2.97 & 2.81 & 2.59 & 2.70 & 4.10 \\
\multirow{2}{*}{ Junior } & Mean & 12.01 & 7.69 & 8.07 & 9.60 & 8.88 & 10.56 & 8.94 & 17.53 \\
& S.E. & 6.92 & 6.72 & 6.92 & 2.94 & 2.77 & 2.76 & 2.65 & 4.18 \\
\multirow{2}{*}{ Senior } & Mean & 10.83 & 6.98 & 7.00 & 9.75 & 9.24 & 10.75 & 9.29 & 17.61 \\
& S.E. & 7.05 & 6.80 & 6.92 & 2.62 & 2.51 & 2.45 & 2.49 & 3.89 \\
\hline
\end{tabular}

Note: S.E. = standard errors, AR = academic rank, PAP = performance-approach goals, MAV = mastery-avoidance goals, MAP = mastery-approach goals, PAV = performance-avoidance goals, and AS = academic self-efficacy. 
Figure 1 depicts the trend of emotional changes of college students from the aspects of stress, depression, and anxiety. For most college students, being a freshman means facing an unfamiliar environment with a brand-new start. In the second year, students' levels of stress, depression, and anxiety all climbed up with the increase of academic pressure and more devotion to social activities. After two years of adaption to college life, students become familiar with the school environment, discover their interests, and are less confused compared to the first two years, which leads to a decline in pressure. However, the levels of depression and anxiety both rise in junior year, as this is the time when most students begin to worry about job hunting, future careers, and making major life choices. As their jobs and future careers settle, students will have great expectations for the future again, and therefore levels of stress, depression, and anxiety are the lowest in senior year. There are also gender differences in the level of stress $(\mathrm{F}$ value $=2.28, p=0.1312)$, depression ( $\mathrm{F}$ value $=3.92, p=0.048)$, and anxiety (F value $=0.51, p=0.476)$. The stress level of females in the freshman, sophomore, and junior year $(12.83,13.28$, and 12.12, respectively) is higher than that of males $(12.47,12.83$, and 11.91, respectively), but the stress level of males in the senior year (10.87) is slightly higher than that of females (10.79). Females demonstrated a higher level of anxiety in freshman (female $=7.68$, male $=7.67$ ) and sophomore stages (female $=8.01$, male $=7.87$ ), but males surpassed females in the junior (female $=7.94$, male $=8.19)$ and senior year $($ female $=6.84$, male $=7.14)$.



Figure 1. The variation tendencies of stress, depression, and anxiety among college students. Analysis of variance between grades: Stress (F value $=39.74, p<0.05)$; depression (F value $=4.91, p<0.05$ ); anxiety $(\mathrm{F}$ value $=11.16, p<0.05)$. Note: The $\mathrm{Y}$ axis indicates negative emotional scores and the $\mathrm{X}$ axis indicates grade.

The fluctuation of achievement goals is demonstrated in Figure 2. Apart from the performance-avoidance goal, which remained stable across the four years, the levels of the mastery-approach, mastery-avoidance, and performance-approach goals all declined in the first three years but bottomed out and rose in the senior year, although not catching up with the freshmen year, which indicates that the students' learning passion continuously declines after enrolment. Although the motivation to learn increased in the senior year, it still did not exceed the level in the first year, 
which shows that the students' will to learn appears to be the strongest when they first enter college. Under such situations, whether the weakening of learning motivation is caused by the students lowing their standards or the unattractive curriculum offered by the college requires further discussion. There are also gender differences in the level of performance-approach (F value $=96.53, p<0.05$ ), mastery-avoidance ( $\mathrm{F}$ value $=8.02, p<0.05)$, mastery-approach $(\mathrm{F}$ value $=9.83, p<0.05)$, and performance-avoidance goals ( $\mathrm{F}$ value $=27.76, p<0.05$ ). The score of females is higher than that of males in all dimensions most of the time, especially in the performance-approach and -avoidance goals, where the disparity is especially obvious. The only exception occurs in the first year, where the scores of the mastery-approach goals of males are slightly higher than those of females by 0.03 . Therefore, we can conclude that female students are more motivated in pursuing academic success compared to male students.

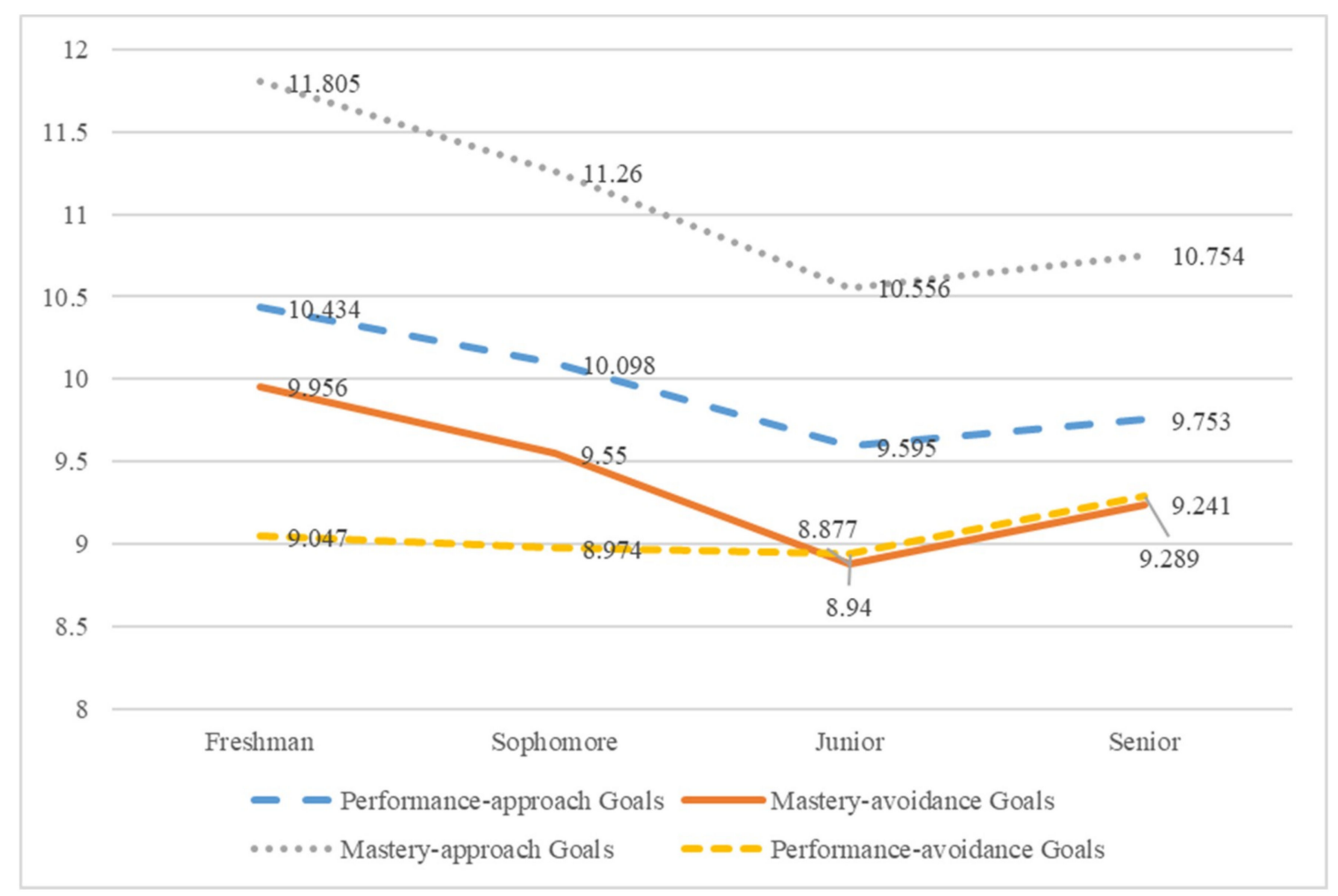

Figure 2. The variation tendency in achievement goals of college students. Analysis of variance between grades: Performance-approach goal $(\mathrm{F}$ value $=34.21, p<0.05)$; mastery-avoidance goal (F value $=57.54$, $p<0.05$ ); mastery-approach goal ( $\mathrm{F}$ value $=95.88, p<0.05)$; performance-avoidance goal $(\mathrm{F}$ value $=7.22$, $p<0.05)$. The $\mathrm{Y}$ axis indicates achievement goal scores and the $\mathrm{X}$ axis indicates grade.

College students' academic self-efficacy also declined from freshman to junior year, which suggests that college students' confidence in completing learning tasks gradually decreased as the classes got more challenging in higher grades. Since China's college curricula are designed to have very few classes in the senior year, students' levels of academic self-efficacy began to move upwards in the final year. As for differences in gender, the academic self-efficacy of male students was higher than that of females in the first two years, indicating male students are more confident when college starts. Although female students' confidence levels and academic expectations were relatively lower in the beginning, they gradually found their advantage, improving in academic self-efficacy and surpassing their male counterparts afterward. This process is shown in Figure 3. 


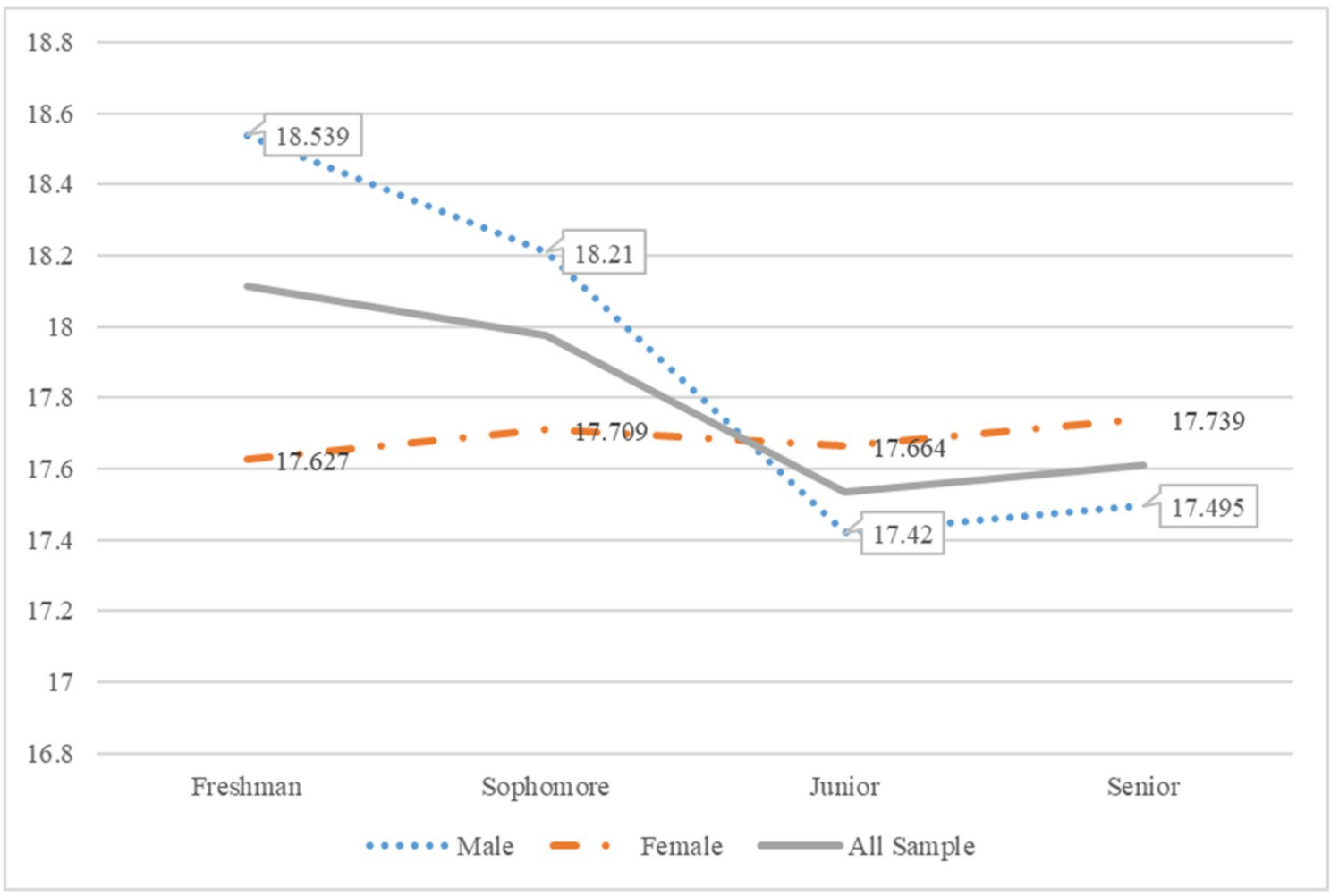

Figure 3. The variation tendency in the academic self-efficacy of college students. Analysis of variance between grades: Academic self-efficacy $(\mathrm{F}$ value $=9.46, p<0.05)$. Analysis of variance between Genders: Performance-approach goals ( $\mathrm{F}$ value $=6.38, p<0.05$ ). The $\mathrm{Y}$ axis indicates the academic self-efficacy scores, and the $\mathrm{X}$ axis indicates grade.

\subsection{Correlation Results}

Table 5 reveals the correlations between academic rank, negative emotions, avoidance, and approaching goals along with significance. Goal achievement (performance-approach, mastery-approach) and self-efficacy $(r>0.25)$ are associated with a better academic rank, while performance-avoidance $(\mathrm{r}=0.2)$ is associated with a lower academic rank. Negative emotion variables, although significant, present a very low correlation with academic achievement $(\mathrm{r}<0.08)$. Mastery-approach goals, performance-approach goals, and mastery-avoidance goals are negatively related to academic rank significantly $(p<0.05)$, which indicates that these three goals are all positive predictors of academic performance. Table 5 shows a positive relationship between achievement avoidance goals and academic rank; thus, the achievement avoidance goal can lead to poor academic performance. As predicted, academic self-efficacy is positively related to academic achievement, which indicates that students with higher academic self-efficacy perform better in academic tests. The indicators of the three negative emotions are highly correlated. The correlation coefficients are 0.815 $(p<0.05)$ between stress and depression, $0.763(p<0.05)$ between stress and anxiety, and $0.855(p<0.05)$ between depression and anxiety. It should be noted that negative emotions are also significantly correlated with achievement goals and academic self-efficacy, and the correlation coefficient between negative emotions and academic self-efficacy is also relatively high $(r>0.18)$. 
Table 5. Correlations between academic rank, negative emotions, avoidance and approaching goals, and self-efficacy.

\begin{tabular}{|c|c|c|c|c|c|c|c|c|}
\hline Correlations & AR & Stress & Depression & Anxiety & PAP & MAV & MAP & PAV \\
\hline Stress & 0.058 * & & & & & & & \\
\hline Depression & 0.058 * & 0.815 * & & & & & & \\
\hline Anxiety & 0.075 * & 0.763 * & 0.855 * & & & & & \\
\hline PAP & $-0.398^{*}$ & $0.059 *$ & $0.026^{*}$ & 0.037 * & & & & \\
\hline MAV & $-0.059 *$ & $0.176^{*}$ & 0.138 * & 0.167 * & $0.478 *$ & & & \\
\hline MAP & -0.254 * & -0.068 * & $-0.120 *$ & $-0.099 *$ & $0.567^{*}$ & $0.523 *$ & & \\
\hline PAV & 0.200 * & 0.110 * & 0.117 * & $0.132 *$ & $0.041 *$ & 0.355 * & 0.023 * & \\
\hline AS & $-0.271 *$ & $-0.181 *$ & $-0.198 *$ & $-0.198 *$ & $0.346^{*}$ & $0.091 *$ & 0.431 * & $-0.086^{*}$ \\
\hline
\end{tabular}

\subsection{Regression Analysis Results}

A linear regression was performed between academic achievement as the dependent variable and emotion, achievement goals, and academic self-efficacy as the independent variables. Demographic factors were taken as control variables. Table 6 presents the results of this regression model after first controlling four demographic factors by entering gender, grade, school, and type of residence as an initial step, followed by the constructs of negative emotion and achievement goals. Model 2 is a mixed OLS (Ordinary Least Square) estimation with all samples, and the result shows that negative emotion and achievement goals collectively explained $26.2 \%$ of the variance in academic performance, which exceeded model 1 to a great extent (5\%). Performance-approach goals, mastery-avoidance goals, performance-avoidance goals, mastery-approach goals, and academic self-efficacy are all significant predictors of academic rank. Performance-approach goals, mastery-approach goals, and academic self-efficacy proved to have a positive effect on academic rank, while higher levels of anxiety, mastery-avoidance goals, and performance-avoidance goals led to a higher academic percentage, indicating worse academic rank. Among the four goal categories in the $2 * 2$ achievement goal framework, the two avoidance goals were positive predictors, and the two approach goals were negative predictors of academic performance. Between the two avoidance goals, performance-avoidance goals $(B=1.728)$ had a greater influence than mastery-avoidance goals $(B=0.675)$. Compared to performance-approach goals $(B=-03.112)$, mastery-approach goals $(B=-0.498)$ revealed a relatively smaller negative correlation with academic performance. Therefore, the impact of the two performance goals on academic rank is greater than that of the predictive value of two mastery goals. The performance-approach goal has the strongest correlation with academic rank, followed by the performance-avoidance goal. Therefore, the conclusion can be reached that having a good level of self-efficacy beliefs $(r=-0.27, B=-0.70$ in model 2 , and $B=-0.23$ in model 7$)$, and performance-approach goals $(\mathrm{r}=-0.04, \mathrm{~B}=-3.11, \mathrm{~B}=-0.85)$ are the two strongest predictors of academic rank, with a lesser effect of mastery-approach goals $(r=-0.25, B=-0.49$, in model 2$)$. Avoidance goals were associated with lower academic rank, namely, avoidance-performance goals $(r=0.2, B=1.82$ in model 2 , and $B=0.37$ in model 7$)$, and to a lesser extent, mastery-avoidance goals $(\mathrm{B}=0.67, \mathrm{~B}=0.20)$.

The effect that the achievement goals and academic self-efficacy have on the academic rank of models 3 to 6 is the same as in model 2. Performance-approach goals, mastery-avoidance goals, and self-efficacy presented a trend of increase across the three years from freshmen to junior year, while mastery-approach goals continued to decrease, and performance-avoidance goals fluctuated. The effects of performance-approach goals, mastery-avoidance goals, mastery-approach goals, and academic self-efficacy all declined in senior year. Since tracking data were involved in this study, turbulence in regression results from the time effect and individual effects of the samples was inevitable for the analysis in models 2 to 6 . Therefore, the two-way fixed effect model was used in model 7 to 
further examine the short panel, and the results are shown in Table 6. Two significant differences were observed between the results of model 7 and models 3 to 6 . First, although the estimation of performance-approach goals, mastery-avoidance goals, performance-avoidance goals, and academic self-efficacy remained positive and significant, the coefficients all reduced in size after controlling for the time effect and individual effect, indicating that the impact that motivational variables had on academic rank was overestimated before the individual effect and time effect were controlled. Second, the effect of mastery-approach goals was reduced to non-significance as students progressed to the next grade, as shown from models 3 to 7 . The coefficient was no longer significant by models 6 and 7 , and it changed from negative to positive in model 7 after controlling for the individual effect and time effect. It can be inferred that the relationship between students' mastery-approach goals and academic rank gradually became insignificant as the grade increased.

Table 6. A summary of regression analyses.

\begin{tabular}{|c|c|c|c|c|c|c|c|c|}
\hline Variables & $\begin{array}{l}\text { Model } 1 \\
\text { All }\end{array}$ & $\begin{array}{c}\text { Model } 2 \\
\text { All }\end{array}$ & $\begin{array}{c}\text { Model } 3 \\
\text { Freshman }\end{array}$ & $\begin{array}{c}\text { Model } 4 \\
\text { Sophomore }\end{array}$ & $\begin{array}{l}\text { Model } 5 \\
\text { Junior }\end{array}$ & $\begin{array}{c}\text { Model } 6 \\
\text { Senior }\end{array}$ & $\begin{array}{c}\text { Model } 7 \\
\text { All }\end{array}$ & $\begin{array}{c}\text { Model } 8 \\
\text { All }\end{array}$ \\
\hline Stress & & $\begin{array}{l}0.00341 \\
(0.0646)\end{array}$ & $\begin{array}{l}-0.116 \\
(0.131)\end{array}$ & $\begin{array}{l}-0.101 \\
(0.114)\end{array}$ & $\begin{array}{l}0.0179 \\
(0.147)\end{array}$ & $\begin{array}{l}0.229 * \\
(0.132)\end{array}$ & $\begin{array}{c}0.0528 \\
(0.0471)\end{array}$ & $\begin{array}{c}0.0518 \\
(0.0476)\end{array}$ \\
\hline Depression & & $\begin{array}{l}-0.0915 \\
(0.0851)\end{array}$ & $\begin{array}{c}0.111 \\
(0.168)\end{array}$ & $\begin{array}{c}-0.0847 \\
(0.157)\end{array}$ & $\begin{array}{l}-0.262 \\
(0.170)\end{array}$ & $\begin{array}{l}-0.119 \\
(0.197)\end{array}$ & $\begin{array}{l}-0.0203 \\
(0.0609)\end{array}$ & $\begin{array}{c}-0.000820 \\
(0.0615)\end{array}$ \\
\hline Anxiety & & $\begin{array}{c}0.136^{*} \\
(0.0745)\end{array}$ & $\begin{array}{l}0.0787 \\
(0.141)\end{array}$ & $\begin{array}{l}0.247^{*} \\
(0.143)\end{array}$ & $\begin{array}{c}0.193 \\
(0.152)\end{array}$ & $\begin{array}{l}0.0272 \\
(0.172)\end{array}$ & $\begin{array}{c}0.106 * \\
(0.0545)\end{array}$ & $\begin{array}{l}0.109 * * \\
(0.0550)\end{array}$ \\
\hline PAP & & $\begin{array}{c}-3.112^{* * * *} \\
(0.105)\end{array}$ & $\begin{array}{c}-2.529 * * * \\
(0.199)\end{array}$ & $\begin{array}{c}-3.008^{* * * *} \\
(0.198)\end{array}$ & $\begin{array}{c}-03.613^{* * *} \\
(0.199)\end{array}$ & $\begin{array}{c}-3.6011^{* * *} \\
(0.251)\end{array}$ & $\begin{array}{c}-0.855^{* * * *} \\
(0.0930)\end{array}$ & \\
\hline MAV & & $\begin{array}{c}0.675^{* * *} \\
(0.116)\end{array}$ & $\begin{array}{l}0.513^{* *} \\
(0.215)\end{array}$ & $\begin{array}{c}0.566^{* * *} \\
(0.218)\end{array}$ & $\begin{array}{c}0.917^{* * *} \\
(0.223)\end{array}$ & $\begin{array}{c}0.832^{* * *} \\
(0.284)\end{array}$ & $\begin{array}{l}0.202^{* *} \\
(0.0935)\end{array}$ & \\
\hline MAP & & $\begin{array}{c}-0.498^{* * *} \\
(0.126)\end{array}$ & $\begin{array}{c}-0.635^{* * *} \\
(0.243)\end{array}$ & $\begin{array}{c}-0.542^{* *} \\
(0.232)\end{array}$ & $\begin{array}{c}-0.472 * \\
(0.246)\end{array}$ & $\begin{array}{l}-0.256 \\
(0.302)\end{array}$ & $\begin{array}{c}0.134 \\
(0.104)\end{array}$ & \\
\hline PAV & & $\begin{array}{l}1.728^{* * *} \\
(0.0961)\end{array}$ & $\begin{array}{c}1.596^{* * *} \\
(0.183)\end{array}$ & $\begin{array}{c}1.917^{* * *} \\
(0.185)\end{array}$ & $\begin{array}{c}1.595^{* * *} \\
(0.189)\end{array}$ & $\begin{array}{c}1.816^{* * *} \\
(0.228)\end{array}$ & $\begin{array}{l}0.377^{* * *} \\
(0.0797)\end{array}$ & \\
\hline AS & & $\begin{array}{c}-0.702 * * * \\
(0.0669)\end{array}$ & $\begin{array}{c}-0.651 * * * \\
(0.119)\end{array}$ & $\begin{array}{c}-0.752^{* * *} \\
(0.128)\end{array}$ & $\begin{array}{c}-0.868^{* * *} \\
(0.131)\end{array}$ & $\begin{array}{c}-0.489^{* * *} \\
(0.169)\end{array}$ & $\begin{array}{c}-0.232 * * * \\
(0.0559)\end{array}$ & \\
\hline Freshman & & & & & & & $\begin{array}{c}-1.736^{* * *} \\
(0.388)\end{array}$ & $\begin{array}{c}-1.605^{* * *} \\
(0.389)\end{array}$ \\
\hline Sophomore & & & & & & & $\begin{array}{c}-3.654^{* * *} \\
(0.405)\end{array}$ & $\begin{array}{c}-3.244^{* * *} \\
(0.393)\end{array}$ \\
\hline Junior & & & & & & & $\begin{array}{c}-5.395^{* * *} \\
(0.405)\end{array}$ & $\begin{array}{c}-4.883^{* * *} \\
(0.397)\end{array}$ \\
\hline Grade & $\begin{array}{c}-1.685^{* * *} \\
(0.235)\end{array}$ & $\begin{array}{c}-2.714^{* * *} \\
(0.214)\end{array}$ & & & & & & \\
\hline School & $\begin{array}{c}-1.262^{* *} \\
(0.559)\end{array}$ & $\begin{array}{c}0.540 \\
(0.495)\end{array}$ & $\begin{array}{l}0.0991 \\
(0.981)\end{array}$ & $\begin{array}{l}-0.363 \\
(0.932)\end{array}$ & $\begin{array}{l}1.178 \\
(1.064)\end{array}$ & $\begin{array}{l}1.290 \\
(0.990)\end{array}$ & & \\
\hline Gender & $\begin{array}{c}-8.598^{* * *} \\
(0.542)\end{array}$ & $\begin{array}{c}-7.026^{* * *} \\
(0.484)\end{array}$ & $\begin{array}{c}-6.644^{* * *} \\
(0.972)\end{array}$ & $\begin{array}{c}-7.052^{* * *} \\
(0.922)\end{array}$ & $\begin{array}{c}-6.339^{* * *} \\
(1.013)\end{array}$ & $\begin{array}{c}-7.706^{* * *} \\
(0.970)\end{array}$ & $\begin{array}{c}4.114 \\
(6.596)\end{array}$ & $\begin{array}{c}4.931 \\
(6.669)\end{array}$ \\
\hline Family location & $\begin{array}{c}-2.226^{* * *} \\
(0.554)\end{array}$ & $\begin{array}{c}-1.840^{* * *} \\
(0.489)\end{array}$ & $\begin{array}{l}-1.496 \\
(1.008)\end{array}$ & $\begin{array}{c}-2.121^{* *} \\
(0.922)\end{array}$ & $\begin{array}{c}-2.039 * * \\
(0.968)\end{array}$ & $\begin{array}{c}-2.057^{* *} \\
(1.029)\end{array}$ & & \\
\hline Constant & $\begin{array}{c}63.13 * * * \\
(1.429)\end{array}$ & $\begin{array}{c}88.47^{* * * *} \\
(2.099)\end{array}$ & $\begin{array}{c}83.01 * * * \\
(4.141)\end{array}$ & $\begin{array}{c}84.26^{* * *} \\
(3.906)\end{array}$ & $\begin{array}{c}85.85^{* * *} \\
(4.042)\end{array}$ & $\begin{array}{c}73.40 * * * \\
(3.869)\end{array}$ & $\begin{array}{c}43.94^{* * *} \\
(9.778)\end{array}$ & $\begin{array}{c}36.49 * * * \\
(9.782)\end{array}$ \\
\hline Sample size & 8210 & 8210 & 2057 & 2051 & 2048 & 2054 & 8210 & 8210 \\
\hline $\mathrm{R} 2$ & 0.036 & 0.262 & 0.229 & 0.302 & 0.291 & 0.222 & 0.055 & 0.032 \\
\hline
\end{tabular}

In summary, the correlated relationship between negative emotions, achievement goals, academic self-efficacy, and academic rank was clarified. While the relationship between achievement goals, academic self-efficacy, and academic rank are significant, it can be deduced that negative emotions do not affect academic rank directly. Two hypotheses could be generated from this situation: (a) Negative emotions might affect academic performance indirectly through a mediating variable, or (b) negative emotions are not significant in model 7 because negative emotions, achievement goals, and academic self-efficacy are highly correlated. To disprove the second hypothesis, we removed achievement goals and academic self-efficiency from the regression and only anxiety, stress, and depression were included in model 8 , and a significant relationship was illustrated between anxiety and academic performance, which was similar to model 7 . Therefore, negative emotions have a relatively weak impact on academic 
rank or otherwise affect academic rank through other variables indirectly. According to the correlation coefficient of Table 5, stress $(r=0.058)$, depression $(r=0.058)$, and anxiety $(r=0.075)$ are all significantly correlated with academic rank. According to the regression analysis results of Table 6 , negative emotions have very little influence on academic rank after controlling for achievement goals and academic self-efficacy. The regression coefficients of stress and depression are not significant in models 2 and 7 and although the regression coefficients of anxiety are significant in models 2 and 7 , the $\beta$ values are very small ( $\beta=0.136$ in model 2 and $\beta=0.106$ in model 7$)$ and are much smaller than the coefficients of the performance-approach goals $(B=-3.112)$, mastery-avoidance goals $(B=675)$, mastery-approach goals $(B=-0.498)$, performance-avoidance goals $(B=1.728)$, and academic self-efficacy $(B=-0.702)$ in model 2. Meanwhile, negative emotions are significantly correlated with achievement goals and academic self-efficacy. Academic self-efficacy $(r>0.18)$ has the highest correlation with negative emotions, followed by mastery-avoidance goals $(r>0.13)$, performance-avoidance goals $(r>0.11)$, mastery-approach goals $(r>0.068)$, and performance-approach goals $(r>0.026)$. Therefore, negative emotions are more likely to have an indirect effect on academic rank via academic self-efficacy and avoidance goals.

\section{Discussions and Conclusions}

\subsection{Discussions}

Academic sustainability refers to the promotion of the academic achievement of students by improving their learning abilities and the research on the impact of the psychological state on academic achievement discusses an important aspect of academic sustainable development. The cognitive factors of college students are relatively fixed, but noncognitive factors, such as mental state, can be modified.

According to the analysis above, $\mathrm{H} 1$ is proved to be true that correlations exist between college students' academic performance and their negative emotions, achievement goals, and academic self-efficacy. Differences exist in the level of negative emotions, achievement goals, and academic self-efficacy among college students of different grades and genders. Stress scored the highest in three negative emotions, therefore comprising the most distinctive characteristics of college students' negative emotional patterns. However, this study finds that stress has no significant impact on academic performance, and only anxiety presents a weak predictive effect on academic performance among all negative emotions, which is quite different from previous studies and verifies H2. Past research has shown that high levels of anxiety and depression have a negative effect on students' academic performance, since they can affect memory as well as concentration $[12,13,17]$, and students with more academic stress are more likely to perform poorly on exams [14]. Achievement goals and academic self-efficacy are not controlled in these studies, so the conclusions may be biased, and negative emotions may not directly affect academic performance.

Among the four goals in the $2 * 2$ achievement goal framework, the two avoidance goals are positive predictors and two approach goals are negative predictors, which means that the avoidance goals are related to poor academic rank and the approach goals are oppositely related. The results proved $\mathrm{H} 3$ and coincides with the results of former studies. Individuals with higher levels of mastery goals will strive to be enterprising and successful [25-28]. Individuals who are performance-avoidant more easily become anxious and worry about undesirable evaluations, which leads to unsatisfying academic performance [32]. What is different from the previous studies is that the performance-approach goals are the most significant predictor of academic performance, followed by performance-avoidance goals, mastery-avoidance goals, and mastery-approach goals. The influence of performance-approach goals and performance-avoidance goals is greater than that of mastery-avoidance goals and mastery-approach goals, which means that performance goals are stronger predictors of a college student's academic performance than mastery goals. 
Academic self-efficacy is a negative predictor of academic rank, which means a higher level of academic self-efficacy contributes to better academic performance, and the $\mathrm{H} 4$ is verified. Academic self-efficacy is an important predictor of academic performance [28], and its positive effect has been confirmed by various complex models [29-32]. However, our research also found that although negative emotions have little predictive effect on academic performance in the regression analysis, they are significantly correlated, which means that negative emotions may indirectly affect academic performance through academic self-efficacy. In other words, higher levels of negative emotions will lead to a decrease of academic self-efficacy and may result in unsatisfying academic performance. Further research and analysis are required to reach more accurate conclusions.

Mastery-approach goals are negatively related to negative emotions, but mastery-avoidance goals are negatively related to anxiety but positively related to stress and depression, which means that college students who are mastery-avoidant may face a higher degree of stress and depression, while those who belong to mastery-approach have a relatively lower level of negative emotions. Performance-approach goals and mastery-approach goals are positively related with academic performance, but having performance-approach goals can lead to a better academic rank than having mastery-approach goals (reject H5). The phenomenon that regards achieving better academic performance as a learning purpose is common in Chinese education system. Students of primary and middle school in China highlight grades in the learning process under the pressure of college entrance examination, but the conclusion of this paper further confirms that Chinese college students are still highly competitive over academic rank, especially those students with higher performance-approach goals, who are able to express themselves in classes and achieve better academic performance than their mastery-approach peers.

\subsection{Conclusions}

The discussions above prove that it is feasible to promote academic performance and improve academic sustainability by adjusting students' mental states, and the specific measures to promote academic sustainable development are as follows.

Firstly, it would be highly beneficial for students if colleges can carry out anxiety-relieving activities on the basis of a regular routine and provide individual counseling to students who are in a poor mental state. Courses focusing on mental health counseling are advised to be included in the college curriculum out of humanistic concern for the students, which would enable them to ameliorate psychological problems, reduce the level of anxiety, and adopt lifelong positive attitudes.

Secondly, the fact that mastery-approach goals rate the highest among the four achievement goals indicates that what matters to college students in their learning process is the acquisition and mastery of knowledge. However, the noted decline in students' academic motivations urges colleges to guide students in their academic endeavors and also to assist them in setting reasonable achievement goals throughout college.

Thirdly, performance-approach goals and academic self-efficacy were identified to have significant promoting effects on academic performance, while mastery-avoidance and performance-avoidance proved to have a negative effect. Further, the importance of supporting self-efficacy was noted as a secure value which is always related to a better academic rank, and additionally, it may be a mediator of negative emotions.

Finally, academic self-efficacy is a vital factor for college students to achieve satisfying academic performance and can also promote students' psychological self-adjustment ability when facing learning obstacles. However, the increasing difficulty of the curriculum has led to the decline in students' academic self-efficacy, and universities should pay attention to improving the students' academic confidence in the teaching process. 


\section{Limitations and Future Directions}

The conclusion of this study is of great significance for universities to construct suitable targets for programs, improve teaching methods, and make certain adjustments to the evaluation system. However, this study still has limitations.

Firstly, due to the constraints of data, this study adopted add-up scores to represent the level of the psychological state in empirical analysis, which is feasible but sacrifices the accuracy of the analysis. Future research can refine the method of data processing.

Secondly, selection bias might exist, since the samples only involved college students from universities in Beijing rather than universities from all provinces in China, which may limit the generalization of the findings. Additionally, because the academic ranking is derived from the student self-report, there may be a bias between the reported value and the actual value. We hope to eliminate this error in in future research by obtaining students' real school performance from their college teaching system.

Thirdly, the study pointed out that negative emotions can affect academic performance indirectly through achievement goals and academic self-efficacy, but no suitable theoretical basis was found to accurately verify this speculation. Further research shall be put forward in this direction.

Finally, measurement invariance is a very important requisite in multiple group structural equation modeling. It attempts to verify that the estimated factors are measuring the same underlying latent construct within each group. However, the research methods used in this paper were the general linear regression model and two-way fixed effect panel regression model from the field of econometrics. Therefore, we did not test the measurement invariance, which is also a limitation of our study. We hope to study and discuss the measurement invariance of this data set in future research.

Concerning prospects for future research, reflection on the relationship between performance-approach goals and academic ranks is necessary, in spite of the fact that this approach is related to lower levels of psychological wellbeing, learning, and growth. Through which variable negative emotions indirectly affect academic performance needs to be confirmed in future studies.

Author Contributions: Conceptualization, X.L. and S.P.; Data curation, X.L.; Formal analysis, X.L.; Funding acquisition, S.P.; Methodology, S.P. and X.G.; Writing—original draft, X.L. and X.G.; Writing—review and editing, X.G.

Funding: This research was funded by "Office of Social Science Planning and Leading Group in Guangzhou", grant number 2018GZGJ204. The APC was funded by “Office of Social Science Planning and Leading Group in Guangzhou".

Acknowledgments: The authors thank National Survey Research Center, Renmin University of China for the support in data collection. The authors thank Juan Hu, Sheng Cui of Renmin University of China for their useful advice.

Conflicts of Interest: The authors declare no conflict of interest.

\section{Appendix A. Depression-Anxiety-Stress Scale}

Please read each statement and circle a number $0,1,2$ or 3 which indicates how much the statement applied to you over the past week. There are no right or wrong answers. Do not spend too much time on any statement.

The rating scale is as follows:

$0=$ Did not apply to me at all;

$1=$ Applied to me to some degree, or some of the time;

2 = Applied to me to a considerable degree, or a good part of time;

3 = Applied to me very much, or most of the time. 


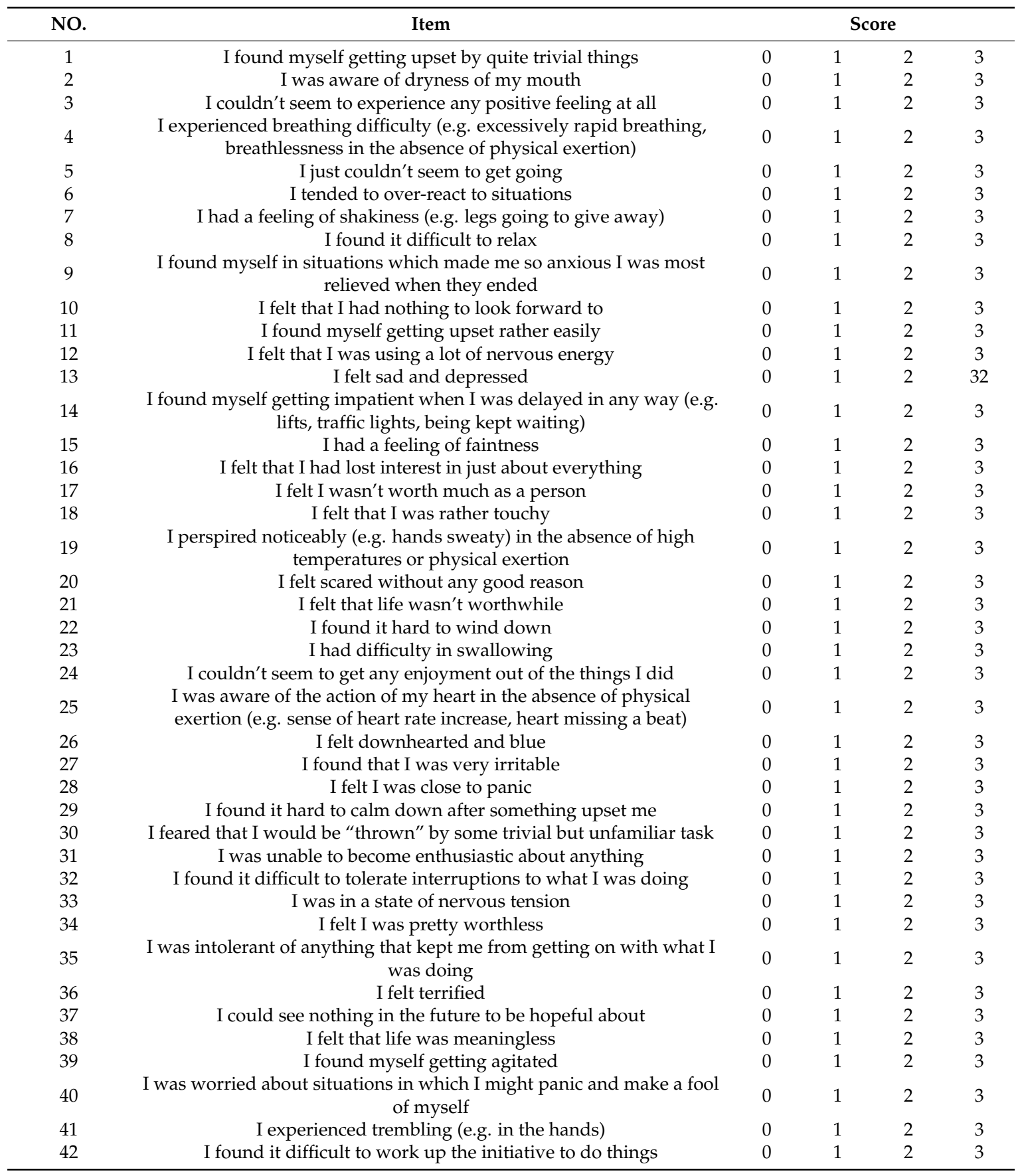

\section{Appendix B. Achievement Goal Scale}

Please read each statement carefully. For each statement, there are five options for you to choose. Please respond to all of the statements and choose the response that best represents your opinion. Only one response can be chosen for each statement.

The rating scale is as follows:

$1=$ "Not at all true";

$3=$ "Somewhat true";

$5=$ "Very true". 


\begin{tabular}{|c|c|c|c|c|c|c|}
\hline \multirow{2}{*}{ NO. } & \multirow{2}{*}{$\begin{array}{l}\text { Item } \\
\begin{array}{l}\text { It is important for me to understand the content of this course as } \\
\text { thoroughly as possible. }\end{array}\end{array}$} & \multicolumn{5}{|c|}{ Score } \\
\hline & & 1 & 2 & 3 & 4 & 5 \\
\hline 2 & It is important for me to do well compared to others in this class. & 1 & 2 & 3 & 4 & 5 \\
\hline 3 & I just want to avoid doing poorly in this class & 1 & 2 & 3 & 4 & 5 \\
\hline 4 & I want to learn as much as possible from this class. & 1 & 2 & 3 & 4 & 5 \\
\hline 5 & I worry that I may not learn all that I possibly could in this class. & 1 & 2 & 3 & 4 & 5 \\
\hline 6 & $\begin{array}{c}\text { My goal in this class is to get a better grade than most of the } \\
\text { other students. }\end{array}$ & 1 & 2 & 3 & 4 & 5 \\
\hline 7 & My goal in this class is to avoid performing poorly. & 1 & 2 & 3 & 4 & 5 \\
\hline 8 & $\begin{array}{l}\text { I am often concerned that I may not learn all that there is to learn } \\
\text { in this class. }\end{array}$ & 1 & 2 & 3 & 4 & 5 \\
\hline 9 & $\begin{array}{l}\text { My fear of performing poorly in this class is often what } \\
\text { motivates me. }\end{array}$ & 1 & 2 & 3 & 4 & 5 \\
\hline 10 & I desire to completely master the material presented in this class. & 1 & 2 & 3 & 4 & 5 \\
\hline 11 & $\begin{array}{c}\text { Sometimes I'm afraid that I may not understand the content of } \\
\text { this class as thoroughly as I'd like. }\end{array}$ & 1 & 2 & 3 & 4 & 5 \\
\hline 12 & It is important for me to do better than other students. & 1 & 2 & 3 & 4 & 5 \\
\hline
\end{tabular}

\section{Appendix C. Academic Self-efficacy Scale}

Please read each statement carefully. For each statement, there are five options for you to choose. Please respond to all of the statements and choose the response that best represents your opinion. Only one response can be chosen for each statement.

The rating scale is as follows:

$1=$ "Not at all true";

$3=$ "Somewhat true";

$5=$ "Very true".

\begin{tabular}{|c|c|c|c|c|c|c|}
\hline \multirow{2}{*}{ NO. } & \multirow{2}{*}{$\begin{array}{c}\text { Item } \\
\text { I'm certain I can master the skills taught in class this year. }\end{array}$} & \multicolumn{5}{|c|}{ Score } \\
\hline & & 1 & 2 & 3 & 4 & 5 \\
\hline 2 & $\begin{array}{c}\text { I'm certain I can figure out how to do the most difficult } \\
\text { class work. }\end{array}$ & 1 & 2 & 3 & 4 & 5 \\
\hline 3 & I can do almost all the work in class if I don't give up. & 1 & 2 & 3 & 4 & 5 \\
\hline 4 & Even if the work is hard, I can learn it. & 1 & 2 & 3 & 4 & 5 \\
\hline 5 & I can do even the hardest work in this class if I try. & 1 & 2 & 3 & 4 & 5 \\
\hline
\end{tabular}

\section{References}

1. Zhou, D. Psychological and behavioral characteristics of the post-90s college students and the strategies for educating and managing them. J. High. Educ. Manag. 2011, 5, 79-83.

2. Yu, Y.; Xiong, Z.; Wang, J. The Status of Mental Health in the Post-90s College Students. J. Liaoning Med. Univ. 2011, 9, 44-47.

3. Yu, S.; Tao, W. A study of the Adaptability and Mental Health State of the post-90s Freshmen. Sci. Soc. Psychol. 2010, 25, 79-84.

4. Di Fabio, A. The Psychology of Sustainability and Sustainable Development for Well-Being in Organizations. Front. Psychol. 2017, 8. [CrossRef] [PubMed]

5. Di Fabio, A. The Psychology of Sustainability and Sustainable Development for Decent Work, Innovation and Social Inclusion: Theory, Research and Practice. Keynote at the One-Day International Conference "Decent Work and Sustainable Development: The Perspective of Existential Psychology for Innovation and Social Inclusion"; Department of Education and Psychology, University of Florence: Florence, Italy, 2018.

6. Di Fabio, A.; Blustein, D.L. (Eds.) Ebook Research Topic from Meaning of Working to Meaningful Lives: The Challenges of Expanding Decent Work; Frontiers Media: Lausanne, Switzerland, 2016. 
7. Di Fabio, A. Promoting Sustainable Development and Well-Being in a Culturally Diverse World. Keynote at the First International Cross-Cultural Conference "Healthier Societies Fostering Healthy Organizations: A Cross-Cultural Perspective"; Department of Education and Psychology, University of Florence: Florence, Italy, 2017.

8. Liu, H.; Shi, Y.; Auden, E.; Rozelle, S. Anxiety in Rural Chinese Children and Adolescents: Comparisons across Provinces and among Subgroups. Int. J. Environ. Res. Public Health 2018, 15, 2087. [CrossRef] [PubMed]

9. Akinci, Z.; Yurcu, G.; Ekin, Y. Relationships between Student Personality Traits, Mobbing, and Depression within the Context of Sustainable Tourism Education: The Case of a Faculty of Tourism. Sustainability 2018, 10, 3418. [CrossRef]

10. Spielberger, C.D. Cross-Cultural Assessment of Emotional States and Personality Traits. Eur. Psychol. 2006, 11, 297-303. [CrossRef]

11. McDonald, A.S. The Prevalence and Effects of Test Anxiety in School Children AU-McDonald, Angus, S. Eur. Psychol. 2001, 21, 89-101.

12. Owens, M.; Stevenson, J.; Hadwin, J.A.; Norgate, R. Anxiety and depression in academic performance: An exploration of the mediating factors of worry and working memory. Sch. Psychol. Int. 2012, 33, 433-449. [CrossRef]

13. Hembree, R. Correlates, Causes, Effects, and Treatment of Test Anxiety. Rev. Educ. Res. 1988, 58, 47-77. [CrossRef]

14. Crego, A.; Carrillo-Diaz, M.; Armfield, J.M.; Romero, M. Stress and Academic Performance in Dental Students: The Role of Coping Strategies and Examination-Related Self-Efficacy. J. Dent. Educ. 2016, 80, 165.

15. Aronen, E.T.; Vuontela, V.; Steenari, M.R.; Salmi, J.; Carlson, S. Working memory, psychiatric symptoms, and academic performance at school. Neurobiol. Learn. Memory 2005, 83, 33-42. [CrossRef]

16. Kayani, S.; Kiyani, T.; Wang, J.; Zagalaz Sánchez, L.M.; Kayani, S.; Qurban, H. Physical Activity and Academic Performance: The Mediating Effect of Self-Esteem and Depression. Sustainability 2018, 10, 3633. [CrossRef]

17. González Hernández, J.; Muñoz-Villena, J.A.; Gómez-López, M. Stress Regulation, Physical Activity, and Perseverance in Spanish Teenagers with Perfectionist Trends. Sustainability 2018, 10, 1489. [CrossRef]

18. Phillips, P.; Abraham, C.; Bond, R. Personality, cognition, and university students' examination performance. Eur. J. Person. 2003, 17, 435-448. [CrossRef]

19. Ames, C. Classrooms: Goals, structures, and student motivation. J. Educ. Psychol. 1992, 84, 261. [CrossRef]

20. Dweck, C.S.; Leggett, E.L. A Social-Cognitive Approach to Motivation and Personality; Psychology Press: New York, NY, USA, 2000; pp. 394-415.

21. Dweck, C.S. Motivational processes affecting learning. Am. Psychol. 1986, 41, 1040-1048. [CrossRef]

22. Elliot, A.J.; McGregor, H.A. A $2 \times 2$ achievement goal framework. J. Pers. Soc. Psychol. 2001, 80, 501-519. [CrossRef] [PubMed]

23. Hulleman, C.S.; Schrager, S.M.; Bodmann, S.M.; Harackiewicz, J.M. A meta-analytic review of achievement goal measures: Different labels for the same constructs or different constructs with similar labels? Psychol. Bull. 2010, 136, 422-449. [CrossRef]

24. Elliot, A.J.; Thrash, T.M. Approach-Avoidance Motivation in Personality: Approach and Avoidance Temperaments and Goals. J. Pers. Soc. Psychol. 2002, 82, 804-818. [CrossRef]

25. Fincham, F.D.; Hokoda, A.; Sanders, R. Learned Helplessness, Test Anxiety, and Academic Achievement: A Longitudinal Analysis. Child Dev. 1989, 60, 138-145. [CrossRef]

26. Stipek, D.; Iver, D.M. Developmental Change in Children's Assessment of Intellectual Competence. Child Dev. 1989, 60, 521-538. [CrossRef]

27. Weiner, B. A Test of Dweck's Model of Achievement Goals as Related to Perceptions of Ability AU-Hayamizu, Toshihiko. J. Exp. Educ. 1991, 59, 226-234.

28. Debacker Roedel, T.; Schraw, G. Beliefs about Intelligence and Academic Goals. Contemp. Educ. Psychol. 1995, 20, 464-468. [CrossRef]

29. Şahin, E.; Çekin, R.; Yazıcılar Özçelik, İ. Predictors of Academic Achievement among Physical Education and Sports Undergraduate Students. Sports 2018, 6, 8. [CrossRef] [PubMed]

30. Daumiller, M.; Dickhäuser, O.; Dresel, M. University instructors' achievement goals for teaching. J. Educ. Psychol. 2019, 111, 131-148. [CrossRef]

31. Abramson, L.Y.; Metalsky, G.I.; Alloy, L.B. Hopelessness depression: A theory-based subtype of depression. Psychol. Rev. 1989, 96, 358-372. [CrossRef] 
32. Smiley, P.A.; Dweck, C.S. Individual Differences in Achievement Goals among Young Children. Child Dev. 1994, 65, 1723-1743. [CrossRef]

33. Bandura, A. Self-efficacy: Toward a unifying theory of behavioral change. Psychol. Rev. 1977, 84, $191-215$. [CrossRef]

34. Bandura, A.; Jourden, F.J. Self-regulatory mechanisms governing the impact of social comparison on complex decision making. J. Pers. Soc. Psychol. 1991, 60, 941-951. [CrossRef]

35. Elias, S.M.; MacDonald, S. Using Past Performance, Proxy Efficacy, and Academic Self-Efficacy to Predict College Performance. J. Appl. Soc. Psychol. 2007, 37, 2518-2531. [CrossRef]

36. Pintrich, P.R.; de Groot, E.V. Motivational and self-regulated learning components of classroom academic performance. J. Educ. Psychol. 1990, 82, 33-40. [CrossRef]

37. Robbins, S.B.; Lauver, K.; Le, H.; Davis, D.; Langley, R.; Carlstrom, A. Do Psychosocial and Study Skill Factors Predict College Outcomes? A Meta-Analysis. Psychol. Bull. 2004, 130, 261-288. [CrossRef] [PubMed]

38. Lucidi, F. Relationship Between Social Context, Self-Efficacy, Motivation, Academic Achievement, and Intention to Drop Out of High School: A Longitudinal Study AU-Alivernini, Fabio. J. Educ. Res. 2011, 104, 241-252.

39. Richardson, M.; Abraham, C.; Bond, R. Psychological correlates of university students' academic performance: A systematic review and meta-analysis. Psychol. Bull. 2012, 138, 353-387. [CrossRef] [PubMed]

40. Coutinho, S.A.; Neuman, G. A model of metacognition, achievement goal orientation, learning style and self-efficacy. Learn. Environ. Res. 2008, 11, 131-151. [CrossRef]

41. Diseth, Å. Self-efficacy, goal orientations and learning strategies as mediators between preceding and subsequent academic achievement. Learn. Individ. Differ. 2011, 21, 191-195. [CrossRef]

42. Ferla, J.; Valcke, M.; Schuyten, G. Judgments of self-perceived academic competence and their differential impact on students' achievement motivation, learning approach, and academic performance. Eur. J. Psychol. Educ. 2010, 25, 519-536. [CrossRef]

43. Pintrich, P.R. A Conceptual Framework for Assessing Motivation and Self-Regulated Learning in College Students. Educ. Psychol. Rev. 2004, 16, 385-407. [CrossRef]

44. Usher, E.L.; Pajares, F. Sources of Self-Efficacy in School: Critical Review of the Literature and Future Directions. Rev. Educ. Res. 2008, 78, 751-796. [CrossRef]

45. Li, L. Chinese University Student Growth Report 2014; Renmin University of China Press: Beijing, China, 2014; pp. 1-60. 